\title{
A judicializaçao dos conflitos de adolescentes infratores: solução ou mito?
}

\author{
Handling adolescent defendants in the courts: \\ solution or myth?
}

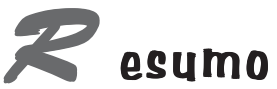

Com o propósito de examinar, através de uma perspectiva crítica, sob quais condições pode o Estado executar a finalidade educativa das medidas e penas aplicáveis aos adolescentes em conflito com a lei, no presente trabalho são analisados os problemas e as limitações de se reduzir a busca de soluções para essas questões à atuação do Estado, através do acesso à justiça, ao Poder Judiciário e às instâncias administrativas de atendimento, como única fonte de direitos e de garantia de direitos. Apontamse as conseqüências negativas de se utilizar a educação como finalidade das medidas e penas aplicáveis nos modelos de justiça juvenil vigentes tanto na Espanha como no Brasil. Com base nesta análise crítica, sugere-se um amplo debate, que implique as partes diretamente envolvidas no conflito, para a construção de alternativas emancipatórias a partir da democratização de respostas que ultrapassem a juridificação da vida e a judicialização dos conflitos.

Palavras-chave: adolescentes infratores, direitos, justiça, medidas socieducativas.

\section{As bstract}

This study seeks to critically examine the conditions under which the state can provide for the education called for in measures and punishments issued to adolescents involved in legal conflicts. It analyzes the problems and limitations caused by reducing the search for solutions to these issues to the activity of the State, through access to the courts, the Judicial System and to administrative care agencies, as the only sources of rights and of a guarantee of rights. It points to the negative consequences of using education as a final goal of the applicable measures and punishments in the juvenile court models in vigor, both in Spain and Brazil. Based on this critical analysis, a broad debate is suggested, which involves the parts directly involved in the conflict in the construction of emancipatory alternatives based on the democratization of responses that go beyond the juridifciation of life and the judicial resolution of conflicts.

Key words: adolescent infractors, rights, justice, social educational measures.

\section{Luciana de Oliveira Monteiro}

Advogada.

Diplomada em Estudos Avançados (DEA) e Doutoranda pelo Programa de Doutorado 'Problemas actuales del Derecho Penal y de la Criminologia'.

Universidade Pablo de Olavide, Sevilha Espanha. 
Violencia sería, como de hecho lo es, que los hombres, seres históricos y necesariamente insertos en un movimiento de búsqueda con otros hombres, no fuesen el sujeto de su propio movimiento.

Es por esto mismo que cualquiera que sea la situación en la cual algunos hombres prohiban a otros que sean sujetos de su búsqueda, se instaura como una situación violenta. No importan los medios utilizados para esta prohibición. Hacerlos objetos, es enajenarlos de sus decisiones, que son transferidas a otro $u$ otros.

Paulo Freire

\section{Introdução}

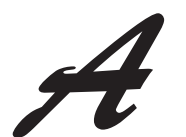

busca de soluções para os casos de conflito de adolescentes com a lei é um tema apaixonante que nos incita a refletir sobre os problemas gerados pela modernidade e a exercitar nossa capacidade criativa na procura de alternativas construtivas e emancipatórias para aqueles que são a continuidade e a esperança do futuro da humanidade.

Neste âmbito, tratar de como se constroem atualmente estas respostas no marco do Estado Democrático de Direito, principalmente pelas mãos do Poder Judiciário, significa partir do princípio de que o "menor" já não corresponde à imagem de sujeito incapaz, imposta entre finais do século XIX e princípios do século XX. E significa, ao mesmo tempo, reconhecer as diferenças que ele possui em relação aos adultos, o que, entretanto, não o qualifica como sujeito hierarquicamente inferior ou débil, mas, sim, como sujeito que possui, ao menos formalmente, um espaço garantido na sociedade para viver e se desenvolver segundo sua condição particular.

A possibilidade desta nova visão sobre o "menor" se estruturou a partir da consolidação do Estado de BemEstar. Seu reconhecimento, a nível formal, como sujeito de direito, é uma construção recente, de finais do século $\mathrm{XX}$, que se vincula à atividade estatal. Neste contexto, é de vital importância analisar as novas pautas de regulação e de intervenção do Estado em relação aos adolescentes, de maneira que o exercício do poder punitivo estatal não entre em conflito com os seus direitos, e verificar se a proposta garantista realmente corresponde à efetividade destes direitos.

Assim, a proposta deste trabalho é examinar, numa uma perspectiva crítica, sob quais condições pode o Estado executar a finalidade educativa das medidas aplicáveis aos adolescentes em conflito com a lei. Objetivo que pretendemos desenvolver a partir do estudo dos modelos formais de intervenção estatal, especificamente os modelos tutelar, educativo, de responsabilidade e de proteção integral. Ademais, para além de uma análise estritamente jurídica, pretendemos apontar as deficiências destes modelos, notadamente dos modelos atualmente vigentes no Brasil e na Espanha, e as bases para a construção de alternativas que ultrapassem o mito da necessária "juridificação" da vida e a "judicialização" de conflitos.

\section{Origem dos modelos de |ustiça |uvenil}

Tratar de modelos de justiça juvenil significa falar de um conjunto de normas aplicáveis a uma faixa da sociedade que se caracterizou, ao largo da história da modernidade (RIVERA BEIRAS, [ca. 2003]), pela sua intrínseca fragilidade físico-psíquica, traduzida em incapacidade e em, conseqüente, necessidade de tutela e proteção. Por esta razão, em sua origem, o que existia era um sistema normativo orientado a um objeto definido: o "menor", cuja incapacidade impedia o reconhecimento de direitos e garantias outorgados aos adultos.

Como categoria jurídica distinta dos adultos ${ }^{1}$, o "menor" surge a finais do século XIX (GARCÍA MENDEZ, 1997) quando, por defeito estrutural da sociedade industrial dessa época, transformou-se em elemento pernicioso e perigoso à segurança coletiva. Vem, enquanto conceito, carregado pelos equívocos do positivismo criminológico e se orienta, no marco da ação do Estado, à estruturação de um sistema corretivo-repressor ${ }^{2}$ diferenciado, justificado com apelo a fundamentos humanitários, em prol da defesa social.

$\mathrm{O}$ "menor" se distingue dos adultos segundo critérios biológicos de idade, localizando-se no tempo, nos anos relacionados à infancia e à juventude, quando o indivíduo se encontra em franco processo de socialização e de desenvolvimento físico-psíquico. O conceito ainda se caracteriza, especialmente neste momento histórico, por selecionar as crianças e os adolescentes que não tiveram acesso às, ou foram expulsos das, instituições básicas de socialização e de controle social existentes para esta faixa da sociedade: a família e a escola. Para esses casos foram criados os tribunais de menores, de caráter essencialmente paternalista-repressivo, os quais, no âmbito científico já indicado, substituíram o tratamento jurídico da criminalidade dos "menores" por um tratamento educativo-terapêutico, sem garantia substancial ou adjetiva $^{3}$. O controle, efetivamente, estendia-se para além da prática de condutas tipificadas como delito, para alcançar a todos aqueles que se situassem no padrão da irregularidade, assumindo o juiz poderes extremamente amplos com grande espaço para a arbitrariedade, de modo que os conflitos, que deveriam ser situados na esfera das políticas sociais, resultaram por ser apropriados pelo Estado, judicializados, criando assim uma categoria marginalizada ${ }^{4}$. 
Assim tem razão García Méndez (1997, p. 41) ao enunciar que

[...] la historia del control social formal de la niñez como estrategia especifica, constituye un ejemplo paradigmático de construcción de una categoría de sujetos débiles para quienes la protección, mucho más que constituir un derecho, resulta una imposición.

Como conseqüência destas construções e da associação entre pobreza, abandono, incapacidade e práticas de delitos, surge a chamada delinqüência juvenil, sobre a qual se estruturaram, ademais do esquema protetor-tutelar, diferentes modelos de controle, cujo eixo na busca de soluções passa necessariamente pelas mãos do Estado, o detentor do monopólio da resolução de conflitos.

\section{Modelos de lustiça luvenil}

Para a construção de um sistema formal de controle dos menores distinto do de adultos, foi necessário delimitar objetivamente quem são os "menores" e porque esta construção adjetiva os faz merecedores de um tratamento diferenciado. Os motivos desta distinção, como foi indicado antes, estavam historicamente baseados na incapacidade do "menor", como conseqüência de sua suposta fragilidade físico-psíquica, que encontrou neste último elemento o seu maior pilar de sustentação, uma vez que a carência de razão e a resultante debilidade ou incapacidade de discernimento, traduzida juridicamente por graus ou ausência de imputabilidade, possibilitou a construção teórica da justificação de sistemas de intervenção estatal diferenciados dos de adultos. A este respeito, cabe averiguar se, efetivamente, o paradigma da incapacidade foi superado. Em relação ao marco objetivo para definir os limites da intervenção, utilizou-se o critério da idade, que se mantém na atualidade.

Assim, delimitada a faixa de idade que caracteriza o "menor", estruturam-se distintos modelos de controle.

\subsection{Modelo tutelar ou de proteção}

Este modelo coincide, nos aspectos histórico e ideológico, com o contexto do surgimento da categoria jurídica do "menor" na modernidade, conforme já referimos. $\mathrm{O}$ panorama deste momento está muito bem descrito por Vásquez González (2003, p. 248):

A finales del siglo XIX y principios del siglo XX, con el nacimiento de la sociedad industrial, la inmigración urbana procedente de sectores rurales $y$, en definitiva, el nacimiento de un nuevo concepto de sociedad, se produce un aumento, sobre todo en las grandes ciudades, de pobreza, marginación y miseria que afecta con fuerza a los niños y jóvenes, llenándose las calles de jóvenes mendigos, vagabundos, rateros y maleantes.

Esta situação suscitou a formulação de uma resposta que, para encobrir uma marcada atuação repressiva e paternalista, buscou suporte em súplicas de ajuda humanitária e se traduziu no grande laboratório de práticas do positivismo criminológico. Assim, o modelo de justiça de "menores", representado institucionalmente pelos tribunais de "menores", estruturou-se a partir de uma série de procedimentos defensivos, educativos e curativos adaptados aos graus de periculosidade e à capacidade de readaptação daqueles delinqüentes, conscientes, mas com uma vontade imatura, atendendo aos imperativos da defesa social e atribuindo às medidas impostas (primordialmente o internamento) o fundamento da prevenção especial, ou seja, a possibilidade de ressocialização através de medidas educativas e curativas (VÁSQUEZ GONZÁLEZ, 2003).

Do ponto de vista constitutivo, este modelo se caracteriza pela declaração da inimputabilidade do menor, trasladando

[...] el juicio sobre sus actos de la esfera de la culpabilidad a la esfera de la peligrosidad. Se considera a los menores delincuentes sumidos en un estado prolongado de inferioridad o de insuficiencia, peligrosos para ellos mismos y para los demás; el peligro que comportan se precave, no por la imposición de una pequeña pena, sino por el ensayo de un régimen prolongado de guarda y educación con el que todos se encuentran bien (CRUZ BLANCA, 2001, p. 85).

Assim, os tribunais de "menores" expandiram sua esfera de competência para além da prática de delitos, interferindo preventivamente no âmbito da vida privada do "menor", cerceando sua liberdade, também quando este se encontrava em situação irregular, ou seja, quando suas condições pessoais, familiares e sociais indicavam um prognóstico de periculosidade. Além do mais, o procedimento para a adoção de medidas era desenvolvido sem as garantias jurídicas típicas do Estado de Direito garantista, de maneira que o que existiu foi um autêntico sistema paternalista e repressor,

[...] administrado informalmente, donde se presta especial atención a una mal entendida protección, asistencia y tratamiento del menor, en donde el factor más importante a la hora de establecer una medida no es el delito, sino la 
personalidad del menor y las circunstancias que lo rodean (CRUZ BLANCA, 2001, p. 90).

Como conseqüência este modelo possibilitou, como marco para a atuação estatal, o "secuestro y judicialización de los problemas sociales" (BELOFF, 1999, p.15), de maneira que todos os conflitos relacionados à infância e à juventude são interpretados como casos ou ameaças de delinqüência. Assim, a resposta intervencionista e repressora do Estado, pelas mãos do Poder Judiciário, ultrapassa a barreira da prática concreta de delitos, rompendo com os limites e garantias do Direito Penal.

\subsection{Modelo educativo}

O modelo educativo surge em alguns países da Europa como oferta do Estado de Bem-Estar e tem como proposta o distanciamento dos "menores" do sistema penal através da aplicação de medidas educativas extrajudiciais, em resposta à prática de condutas anti-sociais (VÁSQUEZ GONZÁLEZ, 2003; CRUZ BLANCA, 2001).

El internamiento (paradigma del sistema tutelar) aparece como el último recurso a utilizar y solamente en casos muy extremos. Se sustituye por una serie de medidas que intentan no alejar al menor de su familia y, en aquellos casos en los que resulta necesario, se intenta que sean lo más parecidas posibles a ésta. Se organizan una serie de medidas e instituciones, dirigidas por trabajadores sociales, como: acogimiento familiar, familias sustitutas, residencias de tipo familiar (con un número limitado de chicos), etc (VÁSQUEZ GONZÁLEZ, 2003, p. 253).

Prevalece neste modelo o critério das necessidades do "menor", estritamente vinculado à ideologia da necessidade de educação (a imposição da educação), o que permitiu a introdução de técnicas desjudicializadas e não formalizadas em prol da não estigmatização do menor (CRUZBLANCA, 2001).

Estas mudanças, enunciadas como positivas, não representaram, entretanto, uma transformação significativa com respeito ao modelo anterior. Isto porque se manteve a ampla possibilidade de interferência do Estado na vida privada do indivíduo, através de instâncias administrativas de atendimento. Nes- te modelo, a interferência se justificava para a imposição de medidas consideradas educativas ou assistenciais, mas que, paradoxalmente, significavam a efetiva restrição de direitos, além de resultar na estigmatização dos "menores" ante a ausência de distinção, para efeito do atendimento, entre infratores da norma penal, "menores" abandonados, enfermos mentais, em processo de desestruturação familiar, etc. Realidade que, em parte, explicava-se pela não aplicação de garantias jurídicas. Aqui, o principal argumento a favor do modelo educativo - o distanciamento do "menor" dos estigmas do sistema penal - acabou por desacreditá-lo, uma vez que a renúncia às garantias formais e substancias do processo abriu espaço para o excesso e o arbítrio na aplicação de medidas socioeducativas.

\subsection{Atual modelo de justiça juvenil: o con- texto da mudança de paradigma}

As conseqüências negativas dos modelos anteriormente expostos derivaram estruturalmente da consideração do "menor" como indivíduo incapaz, alheio aos processos de produção econômica e cultural. Este estigma na sociedade moderna trouxe consigo uma enorme mácula: por um lado significava identificar o "menor" como indivíduo privado de razão, num momento em que a emancipação estava estritamente vinculada ao padrão de cidadania $^{5}$ e racionalidade ao qual o "menor" efetivamente não tinha acesso, estando, portanto, excluído do espaço de reconhecimento de direitos. $\mathrm{E}$ ao não ser sujeito de direitos não se lhe eram asseguradas garantias. Por outro lado significava que a solução para os casos de conflito de "menores" com a lei estava restringida ao marco de atuação estatal, pelas mãos do Poder Judiciário, como centro decisório, e de instâncias administrativas fortemente institucionalizadas, onde se executavam medidas educativas e corretivas.

Assim, a construção jurídica em torno da infância e da juventude nos períodos indicados (finais do século XIX e princípios do século XX, e o pós-segunda guerra) refletiu a incapacidade (aqui sim o termo está empregado em sua verdadeira acepção) do sistema de reconhecer aqueles que não se ajustavam ao conceito de "cidadão", de acordo com o significado que se circunscreve ao processo histórico de configuração do Estado-nação na modernidade ${ }^{6}$ (estigma que na mesma medida alcançou as mulheres, os negros, os pobres, os imigrantes, enfim, todos 
aqueles que não se ajustassem ao dito padrão, ou seja, aqueles que se caracterizaram como "minorias diferenciadas", que, em verdade, correspondem quatro-quintas partes da humanidade) (SANTOS, 2003a). Além disso, constituíram o caldo de cultivo do que ainda hoje podemos chamar de o mito da "juridificação" e "judicialização" dos conflitos sociais, ou seja, o mito de que as respostas aos problemas vividos em sociedade, entre eles a "delinqüência juvenil", devem vir pelas mãos do Estado ${ }^{7}$ através do reconhecimento de direitos e da formalização do acesso aos direitos, como se o Direito e os direitos fossem, "ao mesmo tempo, meios e fins da prática social" (SANTOS, 2003b, p. 36).

Uma mudança no tratamento jurídico do "menor" somente foi possível a partir do momento em que lhe foram reconhecidos, formalmente e sob certas condições ${ }^{8}$, os mesmos direitos e garantias atribuídos ao cidadão.

Historicamente, este período corresponde ao que se tem chamado como geração dos direitos sociais, consolidados com o surgimento do Estado de Bem-Estar e formalmente declarados no Pacto Internacional sobre Direitos Econômicos, Sociais e Culturais de 1966, que nada mais significa que a reinterpretação dos direitos fundamentais civis e políticos, extendidos socialmente, àqueles que são, em certa medida, diferentes (RIVERA BEIRAS, [ca. 2003]). Diferença que não está na essência do indivíduo, uma vez que todos são dotados de extraordinárias capacidades, mas sim na maneira de se expressar e de se conduzir no mundo, levando em consideração os diferentes contextos econômicos, sociais e culturais em que se desenvolveram aquelas capacidades, que dificilmente se aceitariam fora de um estrito padrão de comportamento. O reconhecimento dos direitos sociais introduziu, como um de seus principais avanços, a imposição de obrigações positivas ao Estado para a implementação efetiva dos direitos em prol dos indivíduos, considerados na sociedade a partir de suas diferenças e especificidades, e trouxe, como importante beneficio, a própria mudança do conceito de cidadão.

Sucede que, no processo de construção dos direitos sociais, o reconhecimento formal das crianças e dos adolescentes como sujeitos de direito não aconteceu de maneira imediata e uniforme. Transcorreu de modo lento nos diversos ordenamentos jurídicos e culminou, com seu recente reconhecimento em nível internacional, em uma série de tratados e convenções, cujo referênte mais importante é a Convenção Internacional dos Direitos da Criança, de 20 de novembro de 1989 (CRUZ BLANCA, 2001) ${ }^{9}$.

Como conseqüência sobre a específica realidade dos adolescentes infratores, surgiu a concreta barreira à desmedida intervenção punitiva estatal nos casos de conflito com a lei pela prática de delitos - reduzindo-se ao âmbito de atuação repressiva formalmente autorizada num Estado Democrático de Direito: a do Direito Penal, exercida através do Poder Judiciário, além de determinar ao Estado o cumprimento de uma série de deveres correlatos, a fim de garantir ao adolescente o gozo de seus direitos ${ }^{10}$.

Nesta linha, estruturam-se na Espanha e no Brasil, dois modelos diferenciados de justiça juvenil que, seguindo as diretrizes marcadas pela Convenção Internacional dos Direitos da Criança, incorporaram as garantias substanciais e adjetivas próprias da justiça penal de adultos, centralizando, de forma exclusiva, nas mãos do Poder Judiciário a fonte de respostas legítimas às condutas infratoras, de acordo com o estabelecido pela lei e com o reconhecido como direito.

A análise dos dois modelos se justifica porque estes correspondem a diferentes respostas elaboradas com base nas distintas interpretações do fenômeno da delinqüência juvenil - em razão dos específicos contextos sócioeconômico-político-culturais que caracterizam e distanciam a realidade espanhola da brasileira -, que, entretanto, aproximam-se na medida em que estão inseridas no mesmo âmbito de respostas formalmente admitidas, segundo a moderna concepção do Estado de Direito, atendendo aos limites impostos pelas normativas internacionais.

\subsubsection{0 modelo de responsabilidade espanhol}

Na Espanha, o modelo de justiça juvenil, introduzido pela Lei Orgânica (LO) 5/2000, caracteriza-se, essencialmente, pela tentativa de fusão das garantias jurídicopenais consignadas aos adultos à particular condição do adolescente: o ser humano em desenvolvimento ${ }^{11}$.

Em uma exata síntese, Gómez Rivero (2002, p. 6) descreve que

[...] el 'modelo de responsabilidad', si bien reconoce la necesidad de reservar al menor un trato diferenciado respecto al régimen propio de los adultos, tampoco ignora el riesgo de que bajo dicho velo argumentativo se despoje de garantías a la imposición de lo que es una auténtica pena. Su punto de partida es el reconocimiento de la imputabilidad del menor, aunque disminuida, y, por ello, de la posibilidad de diseñar un régimen de responsabilidad penal. Justamente porque reconoce dicha naturaleza a las sanciones que contempla, parte del carácter eminentemente restrictivo de derechos de cualquier intervención sobre el menor a la par que se esfuerza en dotarle de todas sus garantías tanto desde un punto de vista sustantivo como procesal.

Desta maneira incorporou como princípios gerais: a) a consideração do adolescente como sujeito de direitos, capaz de assumir a responsabilidade por seus atos (capaz 
de culpabilidade); b) a limitação do modelo de justiça de menores à esfera penal pela prática de delitos; c) o princípio de mínima intervenção penal (potencializado pela necessidade de respeito ao processo de desenvolvimento físico-psíquico-social do adolescente); d) a aplicação de medidas alternativas ao internamento; e) a aplicação de medidas privativas de liberdade em casos de extrema gravidade e necessidade; $f$ ) a adoção das garantias penais, materiais e processuais, compatíveis com o princípio de superior interesse do menor.

Neste modelo, em que se determinou a criação de um sistema penal específico para os adolescentes, estes devem participar ativamente nas decisões que possam implicar na restrição de direitos, sobre os quais exercem a titularidade (ainda que não possam dispor deles com autonomia $)^{12}$.

De fato, como indica Bernuz Beneitez (1999, p. 320),

[...] el derecho a ser oído que tiene el menor en toda decisión que le afecte adquiere gran importancia en la Justicia de Menores. Primero, porque a través de la confesión del niño se averiguan las causas que se encuentran detrás de la comisión de la infracción y ponen de manifiesto sus necesidades personales y sociales. Tanto la explicación de las causas de la infracción como de las necesidades del niño contribuyen a diseñar la medida más justa en la relación a las primeras y más adecuada para dar respuesta a las segundas.

Por isso cabe destacar o importante papel que exerce o princípio do superior interesse do menor, entendido, segundo Bernuz Beneitez (1999, p. 148-149), como "[...] el concepto que permite conectar el mundo del derecho con conceptos y problemas sociales. Y, por tanto posibilita la protección del sujeto de derecho". Assim, utilizado como critério interpretativo no modelo de responsabilidade, vincula e limita a atividade estatal na punição e prevenção de delitos à vigência e satisfação simultânea dos direitos dos adolescentes (CILLERO BRUÑOL, 1999).

A Exposição de Motivos da LO 5/2000 (CRUZ BLANCA, 2001) enuncia uma série de princípios interpretativos que, de maneira clara, mas não isenta de críticas, delineia as finalidades do modelo de responsabilidade na Espanha.
Começa por afirmar que

[...] la responsabilidad penal de los menores presenta frente a la de los adultos un carácter primordial de intervención educativa que trasciende a todos los aspectos de su regulación jurídica y que determina considerables diferencias entre el sentido y el procedimiento de las sanciones en uno y otro sector, sin perjuicio de las garantías comunes a todo justiciable (Parágrafo segundo, item 4 , inciso I).

Depois segue com a enumeração expressa dos princípios:

[...] la presente Ley Orgánica ha sido conscientemente guiada por los siguientes principios generales: naturaleza formalmente penal pero materialmente sancionadora-educativa del procedimiento y de las medidas aplicables a los infractores menores de edad, reconocimiento expreso de todas las garantías que se derivan del respeto de los derechos constitucionales y de las especiales exigencias del interés del menor, diferenciación de diversos tramos a efectos procesales y sancionadores en la categoría de infractores menores de edad, flexibilidad en la adopción y ejecución de las medidas aconsejadas por las circunstancias del caso concreto, competencia de las entidades autonómicas relacionadas con la reforma y protección de menores para la ejecución de las medidas impuestas en la sentencia y control judicial de esta ejecución (Parágrafo primeiro, item 6, inciso II).

\section{Como pauta para a atuação estatal,}

- modelo de proteģăo integral

\section{procura reconhecer e promover os}

$$
\text { direitos humanos, econômicos, }
$$

sociais e culturais de crianças

e adolescentes....
Ademais, reitera a natureza sancionadora da Lei e esclarece que a reação jurídica está dirigida à intervenção de caráter educativo de especial intensidade, "rechazando expresamente otras finalidades esenciales del Derecho penal de adultos, como la proporcionalidad entre el hecho y la sanción o la intimidación de los destinatarios de la norma", com o objetivo de "impedir todo aquello que pudiera tener un efecto contraproducente para el menor, como el ejercicio de la acción por la víctima o por otros particulares" (CRUZ BLANCA, 2001, parágrafo primeiro, item 7, inciso II, da Exposição de Motivos da LO 5/2000). 
A leitura dos princípios enunciados sugere, precisamente, a tentativa de estabelecer critérios interpretativos que possibilitem o ajuste dos institutos do Direito Penal de adultos à particular situação do adolescente. Estes matizes estão dirigidos à finalidade da pena, que se orienta claramente à prevenção especial (ressocialização do indivíduo) através da educação, em oposição à pura retribuição e à prevenção geral negativa que se admitem com maiores restrições ${ }^{13}$.

Como enuncia Bernuz Berneitez (1999, p. 135),

En primer lugar, se pretende la rehabilitación del menor y su integración ya que al concebir al menor como sujeto, la reinserción forma parte de las tareas de la sociedad hacia el mismo. Además, la medida mantiene su carácter retributivo en tanto considera al menor como sujeto de derechos, debe asumir con ellos una serie de responsabilidades. En consecuencia, se atribuye a la medida una función importante de prevención general positiva defendiendo que la pena aplicada de forma sistemática, certera y proporcional legitima el sistema.

Em razão destes princípios, que marcam a pauta da atuação estatal na Espanha na persecução dos delitos praticados por adolescentes, sugerimos o debate sobre as finalidades deste Direito Penal de "menores de idade", concretamente a finalidade educativa na execução das penas ou medidas estabelecidas pela LO 5/2000.

Antes de passar a este debate, analisaremos o modelo de justiça introduzido pelo Estatuto da Criança e do Adolescente (ECA) brasileiro que, além de incorporar garantias substantivas e adjetivas próprias do Direito Penal de adultos, também estabelece a finalidade educativa das medidas aplicáveis aos adolescentes pela prática de delitos.

\subsubsection{0 modelo de proteção integral brasileiro}

A proteção integral, interpretada como um princípio garantista, significa a proteção dos direitos das crianças e dos adolescentes, de maneira que através da proteção seja possível garantir a efetivação destes direitos. Como pauta para a atuação estatal, o modelo de proteção integral procura reconhecer e promover os direitos humanos, econômicos, sociais e culturais de crianças e adolescentes.

No Brasil este modelo se concretizou pela elaboração do Estatuto da Criança e do Adolescente (ECA), introduzido pela Lei n. 8069, de 13 de julho de 1990, que representa o micro-sistema jurídico aplicável aos "menores", e está inserido no projeto de incorporação dos princípios do Estado de Bem-Estar e a conseqüente outorga de direitos sociais expressados pela Constituição Federal de 1988. Neste marco, o ECA absorve as ambigüidades do orde- namento jurídico brasileiro no qual, paradoxalmente, convivem o reconhecimento de direitos sociais e a correlata institucionalização de políticas de atendimento social, com um projeto político de desresponsabilização do Estado em relação a seu caráter distributivo. Desta forma o que se vê no âmbito normativo, concretamente no ECA, é uma extensa lista de possibilidades de regulação e de intervenção estatal através da juridificação de situações da vida social como via de prevenção e solução de conflitos que afetam à criança e ao adolescente (FAJARDO, 2003).

Como modelo de justiça juvenil, o ECA se caracteriza por incorporar limites à intervenção estatal pela prática de atos infracionais próprios do Direito Penal, assemelhando-se, neste aspecto, ao modelo de responsabilidade espanhol. Com respeito à finalidade das medidas socioeducativas aplicáveis como conseqüência e resposta pela prática de um ato infracional, o art. 100 do ECA estabelece expressamente que "Na aplicação das medidas levar-se-ão em conta as necessidades pedagógicas, preferindo-se aquelas que visem ao fortalecimento dos vínculos familiares e comunitários".

Desta forma, a finalidade educativa também marca, no modelo brasileiro, a pauta de intervenção legítima do Estado, através de medidas de prevenção e repressão aos casos em que os adolescentes entram em conflito com a lei.

Numa análise precisa, Fajardo (2003, p. 349-351) indica que:

O ECA, assim, 'apresenta-se' como síntese dos modelos protetor e educativo e 'implementa-se' como síntese dos modelos protetor e de justiça. Em termos gerais, o adolescente autor do ato infracional é visto, ao mesmo tempo, como sujeito de direitos e como vitimalobjeto de proteção e educação.

As conseqüencias desta ambigüidade teórica e prática e as possibilidades de implementação poder ser, por exemplo, de três ordens.

Em primeiro lugar, um protecionismo com ênfase terapêutica que reforça a estigmatização, medicaliza a violência, estressa funcionários $e$ resume o trabalho à 'atendimentos' descontextualizados, pontuais, caros, ineficazes e, muitas vezes, de resultados trágicos.

Em segundo lugar, um educativismo retórico, apoiado na falácia da socioeducação como instrumento de transformação social, que desequilibra a balança entre a necessária discricionariedade técnica e o garantismo, que nunca é demasiado. Esta distorção ainda pode embasar a produção de laudos técnicos substancialistas, apoiados no critério do comportamento 'dentro' dos internatos como condição para viver 'fora', em liberdade. 
E, em terceiro lugar, uma visão penalista estreita de justiça juvenil, que reduz as possibilidades de resolução de conflitos fora do sistema judicial, que embasam propostas como redução da idade para imputabilidade penal, aumento de repressão, etc. Esta distorção, ainda, reduz a necessária margem de discricionariedade técnica, coerente com o aspecto pedagógico do trabalho socioeducativo.

Na justiça juvenil brasileira a ambigüidade principal, em resumo, que aparece tanto no texto da lei quanto em sua implementação, é entre o caráter pedagógico e o penal, enquanto secundária, mas que aparece com força na prática, é entre os anteriores e o terapêutico/repressivo. Em nível de discurso, o argumento hegemônico sustenta o caráter pedagógico das medidas socioeducativas (o próprio termo demonstra), mas, em nível de práticas, as características principais são a ausência do caráter pedagógico e a violação do caráter garantista.

Neste contexto, consideramos necessário analisar duas questões: a) se a educação é uma finalidade executável pelo Direito Penal quando adolescentes entram em conflito com a lei, seja pela via do modelo de responsabilidade ou pela via do modelo de proteção integral; e b) se é possível seguir sustentando que as respostas mais eficazes a este problema devam permanecer restritas ao âmbito de atuação estatal, a partir de decisões do Poder Judiciário.

\section{Educar através da pena}

\author{
Como indica Albrecht (1990, p.108),
}

Educación en el sentido de las ciencias sociales es socialización, bajo la cual en una consideración sociológica, psicológica y pedagógica, se entiende un proceso de desarrollo complejo que aspira del educando un desarrollo determinado de personalidad. Educación en este sentido complejo exige una posibilidad de decisión libre del educador - y ciertamente también en consideración a apreciaciones subjetivas. [...] Por lo demás, a una educación adecuada pertenecen también chances de socialización adecuadas, dicho cortamente, circunstancias vitales que permitan un desarrollo de la personalidad.

Quando se desenvolve em um ambiente de autonomia, respeito, participação conjunta e reciprocidade entre educador e educando, a educação supõe um verdadeiro instru- mento de emancipação para a liberdade de eleger e decidir com responsabilidade e consciência das conseqüências das ações individuais para a sociedade. Tal perspectiva, aplicável às crianças e aos adolescentes, parte do pressuposto do reconhecimento de seus direitos, principalmente do direito à igualdade e à liberdade de expressão.

Num sentido contraposto, a educação é uma via de transmissão do conhecimento que, ao ser desenvolvida a nível formal, abarca "no sólo la transmisión, sino también la selección, clasificación, distribución y evaluación (a través de exámenes y pruebas) del conocimiento" (COUSO SALAS, 1999, p. 91). Nesta acepção é um forte instrumento ideológico, possibilitando ao interlocutor dotar de conteúdo e de sentido o objeto do conhecimento, estruturado sobre relações de poder, de modo que "en educación no todo es construcción de personas libres y creativas" (COUSO SALAS, 1999, p. 91), o que afeta diretamente a construção da consciência de coletivo e a correlata noção de responsabilidade no atuar em sociedade.

Na medida em que o Direito Penal se apropria do conceito de educação, o faz contextualizando com a finalidade ressocializadora da pena, transformando-a em instrumento de controle. O objetivo é fazer com que o adolescente seja capaz de aprender e respeitar valores reconhecidos na sociedade, de maneira a promover sua integração como parte desta mesma sociedade, a fim de que não volte a delinqüir. Basta concretamente cumprir através da educação a finalidade da pena: a prevenção de delitos.

A educação que se pretende possível pela via do Direito Penal se circunscreve em grande medida ao sentido contraposto esboçado anteriormente, porque neste contexto não há espaço para a liberdade. De fato, segundo Hassemer e Muñoz Conde (1989, p. 154),

[...] se ha puesto de relieve la incompatibilidad del tratamiento y de cualquier otro objetivo terapéutico con la privación de libertad. 'Educar para la libertad en condiciones de no libertad' es una especie de cuadratura del circulo de difícil solución.

Dessa forma, funciona como um instrumento de imposição ideológica e conformista do ideário de mundo, sociedade e das normas da cultura adulta, executada através da deslegitimação da posição do menor com relação ao adulto (COUSO SALAS, 1999).

A orientação da finalidade da pena para a educação, como instrumento de ressocialização, sugere duas interpretações: a primeira é a associação entre a prática de delitos pelo adolescente ao déficit de aprendizagem. A segunda é a possibilidade de suprir este déficit através da educação pela via da pena ou de medidas socioeducativas. A construção histórica do modelo de justiça de "menores" sobre estas bases, ainda que sejam observadas todas 
as garantias materiais e formais típicas do Direito Penal de adultos, é o prognóstico de seu fracasso, por implicar o mascaramento da mesma estrutura dos modelos anteriores: a consideração do adolescente como indivíduo incapaz e carente de tutela e proteção.

La corrección de los niños y su tratamiento constituyen la señal que identifica principalmente las medidas impuestas por la Justicia de Menores (Mir: 1994, 149). Porque aplican la medida analizando lo que los hechos esconden y pretenden con la imposición de la medida hacerles tomar conciencia sobre el acto y las consecuencias que supuso para el perjudicado. Si trata de diagnosticar en el primer caso y de pronosticar en el segundo actuando sobre el síntoma. En principio, todos los operadores jurídicos y expertos sociales predican la aspiración a lograr, a través de las medidas, una responsabilización del menor por sus actos y su educación conforme a las normas sociales. La eficacia de estas medidas de cara a evitar la reincidencia no ha sido probada. De manera que los expertos sociales justifican la medida por la cobertura del vacío educativo, psicológico o afectivo que presentan estos menores (BERNUZ BENEITEZ, 1999, p. 348).

Executada nestes termos, a finalidade educativa tem o mesmo "sello ideológico de centrar el problema de la criminalidad en el individuo delincuente y no en el sistema social que lo produce" (HASSEMER; MUÑOZ CONDE, 1989, p. 154), além de possibilitar o embuste da aplicação de medidas ou penas severas, com burla à consideração da culpabilidade, em virtude da enunciada "transcendência" do caráter primordial de intervenção educativa. Neste sentido, a legitimação do Direito Penal de adolescentes somente é sustentável na medida em que seja exercido para o reproche pelos delito/ato infracional cometido, "en el sentido de la exigencia de un comportamiento legal" (ALBRECHT, 1990, p. 108-109), considerada a educação não como finalidade da medida ou da pena, mas, sim, como limite (COUSO SALAS, 1999) e parâmetro para a intervenção estatal. Em outras palavras, é necessário desmistificar a educação como tarefa do Direito Penal ou do sistema de justiça juvenil. Sua consideração somente pode ser útil para a limitação da medida/pena no momento de reprimir o adolescente pelo fato cometido e como oferta da Administração (HASSEMER; MUÑOZ CONDE, 1989), em respeito ao seu processo de desenvolvimento físico-psíquico e social. A imposição do aprendizado não deve ser uma finalidade legítima da medida/pena, por implicar numa grave restrição da liberdade subjetiva de convicção do indivíduo sobre si mesmo e os rumos que pretende dar à sua pró- pria vida. Ademais, a tomada de consciência do erro, pelo delito cometido, e a decisão pessoal de mudar, são processos subjetivos que não podem ser controlados pelo Direito Penal. Se o pretendido é tornar o adolescente um sujeito responsável e capaz de conviver em sociedade sem cometer outros delitos, a reprovação do comportamento ilegal através da pena pode de ser uma das vias (a mais dura e perversa) de informação e conhecimento das normas de conduta em sociedade, sobretudo se vem acompanhada da oferta de ferramentas que potencializem o desenvolvimento e o aprendizado, mas que em nenhum aspecto garante que o indivíduo não volte a delinqüir.

$\mathrm{O}$ instrumento mais eficaz, seguramente, seria garantir ao indivíduo, antes que a punição, o acesso às ferramentas para seu desenvolvimento e integração à sociedade, objetivo que se pode cumprir com o apoio da educação, levando em conta que

[...] cualquier propósito de genuina educación $y$ de restitución de derechos pasaría por la implementación de programas ajenos al sistema y a la lógica del derecho penal juvenil. [...] si ha de privilegiarse una intervención verdaderamente educativa y restitutiva de derechos, ello ha de ocurrir fuera del Derecho penal juvenil y lo mejor que puede hacer éste, lejos de 'entusiarmarse' con la idea de educación y pretender hacerla suya, es replegarse todo lo posible renunciando al máximo a una sanción, no sólo si es privativa de libertad, sino, también si es ambulatoria (COUSO SALAS, 1999, p. 97).

Por tudo isso acreditamos que insistir na busca de soluções restritas à atuação do Estado significa permanecer limitado ao âmbito das respostas padronizadas que juridificam e burocratizam as situações da vida em sociedade, distanciando-se das dinâmicas que originam os conflitos sociais, invisibilizando, desta forma, tudo o que está fora do marco de regulação e atuação estatal, provocando a imobilização na construção de alternativas que, desde dentro do problema, poderiam ser mais eficazes.

\section{Conclusões}

Como desdobramento dos argumentos desenvolvidos neste trabalho, consideramos que a finalidade educativa das medidas/penas aplicáveis aos adolescentes em conflito com a lei, nos modelos de justiça juvenil analisados, é um mito que se alimenta para justificar a legitimidade da intervenção estatal como remédio a um problema que pode ser resolvido de maneira eficaz em esferas anteriores à do Direito Penal.

De fato, como atividades que necessitam da participação ativa do adolescente, as medidas/penas com finalida- 
de educativa (enquanto ferramentas utilizadas para a reinserção social) não produzem efeitos positivos quando são aplicadas num ambiente de repressão, violência e privação da liberdade. Pelo contrário, as respostas mais efetivas em benefício do adolescente, para sua reintegração ao seio da família e do entorno social, surgiram de propostas que se caracterizam pela conjugação da atuação do Estado, da família e da sociedade num autêntico processo de apropriação, por parte dos sujeitos diretamente implicados, e de democratização das vias de solução para os casos de conflito que reivindicam, cada vez mais, espaço para a execução em meio aberto e em liberdade ${ }^{14}$.

Desta forma, a finalidade educativa não pode ser concebida enquanto um fim em si mesma. Ela somente pode ser legítima quando é considerada como um referente e um limite à intervenção estatal no exercício do poder punitivo. A pena, no modelo de responsabilidade espanhol, e a medida socioeducativa, no modelo de proteção integral, devem ser aplicadas levando em consideração a necessidade e o direito do adolescente à educação, assim como sua possibilidade de reabilitação a partir da educação, e não como instrumentos de imposição da educação de qualquer maneira e a qualquer preço. Por isso consideramos que o adolescente tem o direito a se opor ao cumprimento da medida/pena educativa que determine sua participação ativa quando esta resulte na imposição de um ato decisório produzido sem sua participação direta e pessoal e que, portanto, não seja respeitoso com o seu direito de se manifestar e de ser escutado.

Ademais, para além do marco de atuação jurídico, consideramos necessário potencializar ações participativas e democráticas, ali onde o conflito com os adolescentes se manifesta, nas quais o recurso ao Direito e ao aparato estatal represente apenas uma ferramenta a mais dentro da multiplicidade de alternativas à solução dos problemas que afetam à juventude.

Com efeito, consideramos que a "juridificação" dos fatos da vida social e a "judicialização" de conflitos devem deixar de ser os eixos da discussão na procura de respostas aos problemas que afetam aos adolescentes que infringem a lei.

Assim, para a conclusão deste trabalho, e como proposta de discussão para o futuro, seguindo a lógica da que implique ativamente as partes diretamente envolvidas no conflito, a sociedade, ONGs, empresas, associações e o Estado, paralela a uma política de democratização da distribuição de recursos, de modo que as desigualdades geradas pela pobreza e hierarquização do ser humano não continuem sendo o motor e o pano de fundo da violência.

\section{Recebido em 05.10.2005. \\ Aprovado em 02.12.2005.}

\section{Referências}

ALBRECHT, M.-A. El Derecho Penal de menores. Tradução Juan Bustos Ramírez. Barcelona: PPU, 1990.

BARATTA, A. Infancia y democracia. In: GARCÍA MÉNDEZ, E.; BELOFF, M. (Comps.). Infancia, ley y democracia en América Latina. Santa Fé de Bogotá: Temis, 1998, p. 31-57.

BELOFF, M. Modelo de la protección integral de los derechos del niño y de la situación irregular: un modelo para armar y otro para desarmar. In: Justicia y Derechos del Niño, Santiago del Chile: UNICEF, Fondo de las Naciones Unidas para la Infancia, Oficina de Área para Argentina, Chile y Uruguay, Ministerio de Justicia, n. 1, nov. 1999, p. 9-21.

BERNUZ BENEITEZ, M. J. De la protección de la infancia a la prevención de la delincuencia. Zaragoza: El Justicia de Aragón, 1999.

CILLERO BRUÑOL, M. El interés superior del niño en el marco de la Convención Internacional sobre los Derechos del Niño. In: Justicia y Derechos del Niño, Santiago del Chile: UNICEF, Fondo de las Naciones Unidas para la Infancia, Oficina de Área para Argentina, Chile y Uruguay, Ministerio de Justicia, n. 1, nov. 1999 , p. 45-62.

COUSO SALAS, J. Problemas teóricos y prácticos del principio de separación de medidas y programas, entre la vía penal-juvenil y la vía de protección especial de derechos. In: Justicia y Derechos 


\section{A judicializaçao dos conflitos de adolescentes infratores: solução ou mito?}

del Niño, Santiago del Chile: UNICEF, Fondo de las Naciones Unidas para la Infancia, Oficina de Área para Argentina, Chile y Uruguay, Ministerio de Justicia, n. 1, nov. 1999, p. 79-104.

CRUZ BLANCA, M. J. Derecho penal de menores (Ley Orgánica $5 / 2000$, reguladora de la responsabilidad penal de los menores). Madrid: Instituto de Criminología de Madrid, Editoriales de Derecho Reunidas, 2001.

DEL ÁGUILA, R. Política, ciudadanía y juicio. In: V. V. A. A. $L a$ política. Ensayos de definición. Madrid: Sequitur, 2000.

FAJARDO, S. P. Retórica e realidade dos direitos da criança e do adolescente no Brasil: uma análise sociojurídica da Lei Federal n. 8069, de 13 de julho de 1990. 2003. Tese (Doutorado em Direitos Humanos e Liberdades Fundamentais) - Universidade de Zaragoza. Zaragoza, 2003

FREIRE, P. Pedagogía del oprimido. Tradución Jorge Mellado. Madrid: Siglo XXI, 1988.

GARCÍA MÉNDEZ, E. La Convención Internacional de los Derechos del niño: del menor como objeto de la compasión-represión a la infancia-adolescencia como sujeto de derechos. In: Derecho de la infancia/adolescencia en América Latina: de la situación irregular a la protección integral. Disponível em <www.iir.oea.org/ la_convencion_internacional.pdf $>$.Acesso em 21 jan. 2004.

Para una historia del control socio-penal de la infancia: la informalidad de los mecanismos formales de control social. In: Derecho de la infancia-adolescencia en América Latina. Ibagué: Forum Pacis, 1997.

GÓMEZ RIVERO, M. C. La nueva responsabilidad penal del menor: las Leyes Orgánicas 5/2000 y 7/2000. Revista Penal, Universitat Jaume I, Castelló de la Plana, Espana, n. 9, p. 3-26, 2002.

HASSEMER, W.; MUÑOZ CONDE, F. Introducción a la criminología y al Derecho Penal. Valencia: Tirant lo blanch, 1989.

ILANUD - Instituto Latino-Americano das Nações Unidas para Prevenção do Delito e Tratamento do Delinquente. SócioEducação no Brasil: Adolescentes em conflito com a lei. Experiências de medidas sócio-educativas. 1. e 2. ed. São Paulo: publicação da comissão organizadora do Prêmio SócioEducando, [ca. 2003].

RIVERA BEIRAS, I. Nacimiento y presupuestos ideológicos de la justicia penal juvenil. In: SNEIDER RIVERA (Comp.). Pasado $y$ presente de la justicia penal juvenil. Unicef/Universidad de Barcelona [ca. 2003], p. 7-19.

. Disposiciones internacionales y jurisprudencia relevante en materia penal juvenil. In: SNEIDER RIVERA (Comp.). Pasado $y$ presente de la justicia penal juvenil. Unicef/Universidad de Barcelona [ca. 2003], p. 43-64.

SABARIEGO GÓMEZ, M. J. La globalización de las relaciones entre cultura y política: una nueva ecologia social de la identificación. In: V.V.A.A. Investigación de la paz y los Derechos Humanos desde Andalucía. Granada: Eirene, 2005, p. 107-117.

SANTOS, Boaventura de Sousa. Crítica de la razón indolente. Bilbao: Desclée de Brouwer, 2003a.
Poderá o direito ser emancipatório? Revista Crítica de Ciências Sociais. Coimbra, n. 65, p. 3-76, 2003 b.

TAMARIT SUMALLA, J. M. El nuevo Derecho Penal de menores: ¿creación de un sistema penal menor? Revista Penal, Universitat Jaume I, Castelló de la Plana, Espana, n. 8, p. 71-89, 2001.

\section{Notas}

1 Neste trabalho vinculamos o surgimento do menor, enquanto categoria jurídica distinta da dos adultos, à estruturação do primeiro Tribunal de Menores criado no final do século XIX, precisamente em Chicago, em 1899, que estabeleceu uma jurisdição própria e autônoma para crianças e adolescentes, com a intenção de oferecer um tratamento diferenciado aos menores delinqüentes, que antes eram apenados nas mesmas bases que os adultos, com fundamento na culpabilidade de caráter retributivo. Conforme Tamarit Sumalla (2001), este momento corresponde ao modelo de justiça fundamentado no discernimento. Para aprofundar neste tema, indicamos Cruz Blanca (2001).

2 Para uma síntese dos reflexos do positivismo criminológico no sistema de controle formal dos menores, indicamos. Rivera Beiras (199-).

3 Sobre o processo sociocultural de construção da subcategoria do menor e sua introdução na cultura sociojurídica do modelo protetor-repressivo de menores, consideramos importante indicar a leitura de García Méndez (2004).

4 Sobre a doutrina da situação irregular, vide Beloff(1999).

5 Em uma das interpretações mais comuns da idéia de cidadania (elemento que outorga ao indivíduo/cidadão/nacional direitos específicos sobre o território e os recursos, não só materiais, mas também simbólicos), vê-se que está vinculada à integração do indivíduo a um grupo nacional em um determinado território "sobre" o qual tem direitos (SABARIEGO GÓMEZ, 2005).

6 No Estado Moderno o conceito de cidadania está estritamente vinculado aos princípios que emanam da declaração formal de igualdade e liberdade. Para aprofundar neste tema, vide Del Águila (2000).

7 Para um estudo mais aprofundado das representações do Estado geradas pelo mito da juridificação e da judicialização dos conflitos sociais, vide Fajardo (2003).

8 Condições que se referem ao exercício efetivo destes direitos.

9 O reconhecimento do menor como sujeito de direitos em nível internacional está, ademais da Convenção Internacional dos Direitos da Criança, de 20 de novembro de 1989, nas Regras Mínimas das Nações Unidas para a Administração da Justiça a Menores (Regras de Beijing) de 1985, nas Regras das Nações Unidas para a Prevenção da Delinqüência Juvenil (Diretrizes de Riad), de 1990 e nas Regras das Nações Unidas para a Proteção dos Menores Privados de Liberdade.

10 Apesar da importância do reconhecimento do menor como sujeito de direitos, cabe advertir que a implementação e a 
garantia destes direitos estão vinculadas ao desenvolvimento de políticas sociais básicas, sem as quais o reconhecimento formal não serviria a outra finalidade que ao exercício simbólico e inócuo da retórica (BARATTA, 1998).

11 Cabe advertir que apesar da semelhança existente entre o modelo de responsabilidade e o de proteção integral, desenvolvido na América Latina, isto não implica na necessária equivalência de tratamento da delinqüência juvenil em ambos, entretanto é inegável reconhecer a origem dos dois modelos nas mesmas diretrizes internacionais.

12 A Convenção Internacional sobre os Direitos da Criança, de 1989, estabelece, nos artigos 5 e 12, o princípio de autonomia progressiva do menor no exercício de seus direitos e de participação em todos os assuntos que lhe afetem, declarando expressamente o direito de se manifestar, correlato ao direito de ser escutado.

13 Para uma reflexão sobre as finalidades da pena no Direito Penal de menores na Espanha, vide Gómez Rivero,(2002).

14 A confirmação desta realidade pode ser vista nas experiências concretas referidas em ILANUD [ca. 2003].

\section{Luciana de Oliveira Monteiro}

luciana.lumonteiro@gmail.com

Universidad Pablo de Olavide

Crta. Utrera, Km 1

Sevilla - España

41013 